\title{
EXPERIÊNCIA DE ESCUTA PSICOLÓGICA NA CLÍNICA MÉDICA DO HOSPITAL REGIONAL DE ASSIS
}

\author{
Bianca Paes, Vanessa Sabino da Silva Dantas, Camila Rippi Moreno, Maria Luísa Louro de Castro \\ Valente \\ Universidade Estadual Paulista - UNESP. Curso de Psicologia, Assis - SP. E-mail: bi paes@hotmail.com
}

\section{RESUMO}

O papel do psicólogo no contexto hospitalar vai além das expectativas de cura, contribuindo na relação do paciente. Objetivo: realizar uma escuta clínica e psicológica aos pacientes internados, investigando os motivos da internação. Metodologia: utiliza-se um roteiro de entrevista semiestruturado que coleta dados pessoais, explora os motivos da internação, a história pregressa da doença e da sua vida. Resultados e Discussão: No período de agosto a novembro de 2013 foram realizadas 44 entrevistas, sendo 35 pacientes e 9 acompanhantes. Ressalta-se que em alguns casos o acompanhante estava presente no momento da intervenção psicológica e participava da mesma. Observa-se que a situação de hospitalização é vivida de forma muito particular por cada indivíduo. Conclui-se que o trabalho da Psicologia na Clínica Médica permite que os pacientes sejam ouvidos a partir de uma escuta diferenciada por parte do estagiário, para que possam deixar o hospital fortalecido e buscando sua recuperação.

Palavras-chave: Psicologia da Saúde, Psicologia Hospitalar, Clínica Médica, Hospital Regional de Assis, Estágio.

\section{PSYCHOLOGICAL LISTENING EXPERIENCE IN THE MEDICAL CLINIC OF THE HOSPITAL IN THE CITY ASSIS}

\begin{abstract}
The psychologist duty in the hospital context exceeds cure expectations: it contributes in the relationship of the patient. Objective: to make a clinic and psychological hearing to hospitalized patients to investigate the reasons of the hospital admission. Methodology: it is used a semistructured interview guide which collects personal data, explores the reasons of the hospital admission, the previous story of the disease and the patient's life. Results and discussion: In the period between August and November in 2013, 44 interviews were made, 35 were made with patients and 9 with accompanying people. It is important to stress that, in some cases, the accompanying person was in the moment of the psychological intervention and participated in it. It is possible to suppose that the situation of the patient in the moment he/she is hospitalized is experienced in a very particular way by each one of them. It is clear from it that the Psychology work in Medical Clinic allows patients to be listened from a different hearing by the psychology trainee so they can leave the hospital strengthened and prepared.
\end{abstract}

Keywords: Health Psychology, Hospital Psychology, Medical Clinic, Hospital Regional from Assis, Psychology Traineeship. 
Sabe-se que o papel do psicólogo no contexto hospitalar vai além das expectativas de cura, pois ele contribui de maneira relevante na relação do paciente consigo mesmo, com a sua doença e com a equipe, buscando ver a pessoa como um todo, com foco no sujeito e não somente na doença. A partir disso, o presente trabalho apresenta a Clínica Médica do Hospital Regional de Assis, bem como seu funcionamento e o estágio que foi realizado na mesma por estudantes de psicologia da UNESP - Assis no ano de 2013. O trabalho esteve sob supervisão das professoras do curso de graduação em Psicologia da Unesp - campus de Assis, Dra. Maria Luisa Louro de Castro Valente, Dra. Helena Rinaldi Rosa e Dra. Mary Yoko Okamoto. Foi executado pelos alunos dos quarto e quinto anos do curso, que se distribuem nas diversas clínicas do hospital: Psiquiatria, Médica, Cirúrgica, Gestação de Risco, Mães Alojadas e, no ano de 2013, também na sala de espera da UTI.As atividades realizadas no ano de 2013 tiveram início em agosto, após a preparação teórica dos alunos, e foramfinalizadas em dezembro.

A Clínica Médica foi o primeiro setor do HRA que se interessou em desenvolver seu trabalho nos moldes da Clínica Ampliada, conceito de trabalho em saúde proposto pela Política Nacional de Humanização do SUS (PNH).

\section{HOSPITALIZAÇÃO}

Entende-se por hospitalização o confinamento de um paciente na instituição hospitalar (Romano, 2003). De acordo com Angerami-Camon (2003), uma doença nunca é a mesma para diferentes pessoas. Nesse sentido, observa-se que a situação de hospitalização é vivida de forma muito particular por cada indivíduo. Segundo Albernaz (2003), Eksterman (1994) e Romano (2003), os significados destes processos estão ligados à constituição familiar, cultural e emocional, a crenças e valores e dependem também de fatores como a idade, sexo, escolaridade, momento da vida produtiva, caráter da enfermidade e o suporte de pessoas afetivamente significativas.

\section{CARACTERIZAÇÃO DA CLÍNICA MÉDICA}

O setor da Clínica Médica oferece atendimento a diversos quadros clínicos, tais como problemas cardiorrespiratórios, vasculares, tumores, problemas renais, de fígado, estômago, intestino e pâncreas, entre outros. Chamou a atenção no ano de 2013 a grande presença de casos de hipertensão arterial (HAS), o que levou à elaboração de folhetos sobre a prevenção e tratamento da doença, principalmente para os pacientes da clínica médica. 
Há 32 leitos, distribuídos em número de quatro por cada quarto do hospital; de um lado do corredor ficam os leitos masculinos e do outro lado, os leitos femininos. Cada médico, de especialidade específica, fica responsável por um quarto, diariamente.

\section{SOBRE OS ATENDIMENTOS}

A intervenção do psicólogo no contexto hospitalar em conjunto com outros profissionais da saúde que atuam nesta instituição é de grande importância para a promoção da saúde social, emocional e física do paciente. Para Chiattone (1984), o papel do psicólogo no hospital pode revitalizar vidas que muitas vezes agonizam dentro do hospital. Em concordância, AngeramiCamon (1984) relata que é inegável o conforto que o psicólogo traz aos pacientes hospitalizados, visto que a sua ação busca a diminuição das angústias e dos sofrimentos provocados pelo processo da hospitalização. Este pensamento reafirma a importância da inserção deste profissional nos atendimentos diários dos serviços em hospital geral.

De acordo com a observação e a experiência dos estagiários, o contato entre os profissionais de várias áreas dentro do hospital facilita o trabalho com o paciente, proporcionando diferentes subsídios para atender esta demanda e, favorecendo o processo de alta, bem como o tratamento integrado, ampliando o auxílio prestado ao doente e à sua família.

Dessa forma, os objetivos desse trabalho consistem no contato com o paciente para a compreensão do caso e a intervenção psicológica no momento da internação; fornecer uma escuta clínica e psicológica aos pacientes internados e seus acompanhantes e, também, introduzir os alunos na prática da psicologia hospitalar, colocando-os em contato com o funcionamento desta instituição e realizando, assim, aprendizagem significativa para a sua formação.

\section{MÉTODO}

Para cada clínica do hospital foi elaborada uma entrevista semiestruturada de avaliação psicológica. Na Clínica Médica, a entrevista é orientada para a psicodinâmica da estrutura intrapsíquica e do funcionamento interpessoal, buscando estar-se atento ao que está implícito na comunicação. Procurou-se, ainda, abordar assuntos do cotidiano do paciente a fim de avaliar melhor sua psicodinâmica.

Em cada atendimento realizado, buscou-se oferecer um acolhimento e uma escuta diferenciada, que pode ser chamada de Interventiva. Inicialmente, ao abordar o paciente, é dada a possibilidade de escolha quanto à intervenção psicológica. Com aqueles que aceitam conversar, a escuta é voltada não apenas para o estabelecido no roteiro de entrevista, mas também aos 
familiares e acompanhantes bem como à equipe que trazia questões e levantava possíveis conflitos nas relações imbricadas do ambiente hospitalar.

Em 2013 duas estagiárias compareceram semanalmente ao setor, por um período de quatro horas. O projeto foi previamente avaliado e aprovado pelo Comitê de Ética em pesquisa da UNESP da FCL de Assis com o registro no.048/2011.

\section{RESULTADOS}

A Tabela 1 apresenta o número de atendimentos realizados em 2013, na Clínica Médica, pelas duas estagiárias do setor.

Tabela 1. Distribuição da população atendida por estagiário e meses, em número e porcentagem

\begin{tabular}{cccccc}
\hline Estagiária & Agosto & Setembro & Outubro & Novembro & Total \\
\hline A & 8 & 5 & 4 & 5 & 22 \\
B & 8 & 7 & 1 & 6 & 22 \\
\hline Total & 16 & 12 & 5 & 11 & 44 \\
\hline
\end{tabular}

Foram realizadas 44 entrevistas realizadas e atendidos 35 pacientes, além de 9 acompanhantes, atendidos ou pelas impossibilidade de comunicação com o paciente ou por trazerem sua própria demanda.Porém, essa conversa era geralmente ao lado do leito do respectivo paciente de quem se falava na entrevista, portanto, o mesmo ouvia e participava de certa forma da intervenção, neste sentido pode-se falar que a interação com ele não foi direta, mas não foi inexistente. Muitas vezes, o acompanhante estava presente no momento da intervenção psicológica e participava da mesma, falando da trajetória da doença e da história de vida do paciente junto com ele e, dessa forma, expressando o seu ponto de vista e sua angústia diante da internação.

A Tabela 2 apresenta a distribuição de pacientes por sexo.

Tabela 2. Distribuição da população atendida por sexo, em número e em porcentagem

\begin{tabular}{lcc}
\hline \multicolumn{1}{c}{ SEXO } & NÚMERO & $\%$ \\
\hline Feminino & 18 & 51,4 \\
Masculino & 17 & 48,6 \\
\hline TOTAL & 35 & 100 \\
\hline
\end{tabular}

A tabela 2 indica que não há diferença entre o número de atendimentos de homens e de mulheres. 
A Tabela 3 apresenta a distribuição da população por faixa etária.

Tabela 3. Distribuição da população atendida por faixa etária em número e em porcentagem

\begin{tabular}{llr}
\hline IDADE & NÚMERO & $\%$ \\
\hline 21-30 anos & 8 & 22,8 \\
31-40 anos & 4 & 11,4 \\
41-50 anos & 2 & 5,7 \\
51-60 anos & 9 & 25,7 \\
61-70 anos & 3 & 8,6 \\
71-80 anos & 5 & 14,3 \\
81-90 anos 4 & 11,4 \\
\hline TOTAL: 35 & 100 \\
\hline
\end{tabular}

Nota-se a partir da tabela que a faixa etária mais presente entre os pacientes entrevistados foi a de 51-60 anos e a menos presente foi a de 41-50 anos. Sabe-se que na Clínica Médica comumente há predominância de internações de pessoas idosas, devido a doenças crônicas que vão se agravando com o passar do tempo e à menor resistência às doenças. Contudo, por ser um setor do hospital que abarca um leque diversificado de enfermidades, encontravam-se, em menor quantidade, pessoas jovens. Nestas, as internações foram devidas a quadro clínico já avançado, tais como linfoma, diabetes, AIDS sem uso correto de medicamento, ou mesmo, consequência de acidentes.

Nas avaliações realizadas, buscou-se caracterizar o estado emocional do paciente no momento da entrevista, que é apresentado de forma sintética na Tabela 4; as categorias criadas referem-se a:

- Um estado positivo, de bem estar, tranquilidade e conformidade com a doença e a necessidade de internação;

- Estados considerados não tão positivos, tais como ansiedade, depressão, ou mesmo preocupações;

- Casos em que o entrevistado revelava muita angústia e tristeza de se encontrar na situação de internação;

- Paciente que se encontravam tensos e nervosos com a internação, demonstrando irritabilidade e intolerância;

- Na categoria "outros" incluem-se casos em que não foi possível avaliar o estado emocional do paciente. 
Tabela 4. Estados Emocionais no momento da entrevista

\begin{tabular}{lcc}
\hline & Número & $\%$ \\
\hline Positivo & 13 & 37,1 \\
Ansiedade, Depressão & 05 & 14,3 \\
Angústia, Tristeza & 10 & 28,6 \\
Tensão, Nervoso & 05 & 14,3 \\
Outros & 02 & 5,7 \\
\hline Total & $\mathbf{3 5}$ & $\mathbf{1 0 0}$ \\
\hline
\end{tabular}

Observa-se que, apesar de a maioria dos pacientes encontrar-se, no momento em que ocorreu a primeira avaliação, em um estado emocional considerado positivo, de tranquilidade e de aceitação da doença e do tratamento, o número de pacientes avaliados negativamente (ansiedade, depressão, angústia, tristeza, tensão, nervoso) foi maior (20). Entende-se que a situação de hospitalização é vivida de forma muito particular por cada indivíduo e que os significados destes processos estão ligados a diversos fatores. Pode-se também levantar a hipótese de que a escuta dos estagiários ainda não se instalou adequadamente, o que pode levar a interpretações eventualmente equivocadas.

\section{DISCUSSÃO: A EXPERIÊNCIA NA CLÍNICA MÉDICA, TRAZENDO QUESTÕES SUBJETIVAS.}

A experiência do estágio no contexto hospitalar foi algo inovador, pois a partir disso, foi possível observar a prática das Políticas Públicas no campo da saúde. O trabalho do psicólogo neste novo espaço ainda está em construção, visto que a entrada da Psicologia no campo da saúde no Brasil é relativamente recente, pois ocorreu somente a partir de 1990 (Sousa \& Coleta, 2012), e fez com que as estagiárias adaptassem sua escuta à diferença de espaço e tempo, treinando a capacidade de captar as manifestações mais sutis de sofrimento psíquico dos entrevistados.

A partir disso, foi possível refletir que uma integração efetiva da equipe é imprescindível para perceber o ser humano como um todo, pois muitas vezes o modelo hegemônico acaba fragmentando-o em seus mais variados âmbitos: biológico, psicológico e social. A ruptura entre mente, corpo e sociedade faz com que se perca a dimensão biopsicossocial que a natureza humana engloba. Por isso, ressalta-se a relevância das estagiárias manterem interação com os médicos e enfermeiros, para assim compreenderem melhor a doença e as necessidades de cada paciente entrevistado, assim como a relevância da Psicologia nessa instituição. 


\section{CONCLUSÃO}

Conclui-se que o papel do psicólogo no contexto hospitalar transcende a filosofia da cura, pois ele pode fazer muito no âmbito da relação do usuário consigo mesmo e com seu sintoma. Ele vai além da cura ao considerar que o sujeito excede os sintomas e a causa da doença pois, no tocante a ela, permanece também a angústia, os traumas, as desilusões, os medos, as consequências reais ou imaginárias, ou seja, as marcas da doença.

Segundo Speroni (2006, s/p.), o lugar do psicólogo no hospital "consiste, portanto, essencialmente em um lugar de escuta, mas de uma escuta diferenciada e privilegiada, na medida em que é a porta de entrada para um mundo de significados e sentidos". Busca-se, assim, que os pacientes sejam ouvidos a partir de uma escuta clínica e interventiva para que possam deixar o hospital fortalecido e preparado para o enfrentamento da doença e a recuperação da saúde.

\section{REFERÊNCIAS}

ANGERAMI-CAMON, Valdemar. Psicologia hospitalar: a atuação do psicólogo no contexto hospitalar. São Paulo: Traço Editora, 1984.

ANGERAMI-CAMON, Valdemar. E a psicologia entrou no hospital. São Paulo: Pioneira Thomson Learning, 2003.

ALBERNAZ, Marcela. O processo de subjetivação no espaço hospitalar: uma reflexão sobre a necessidade de humanização. Monografia, UniCEUB, Brasília, 2003.

CHIATTONE, H.B.C. Relato de experiência de intervenção psicológica junto a crianças hospitalizadas. In.: Valdemar Angerami-Calmon (org.). Psicologia hospitalar: a atuação do psicólogo no contexto hospitalar. São Paulo: Traço Editora, 1984.

EKSTERMAN, Abram. Abordagem psicodinâmica dos sintomas somáticos. Revista Brasileira de Psicanálise, 28(1), s/p., 1994.

ROMANO, Wilma. Princípios para a prática da psicologia clínica em Hospitais. São Paulo: Casa do Psicólogo, 2003.

SOUSA, Alline; Coleta, Marília. O Bem-Estar no Trabalho de Psicólogos em Serviços de Saúde Pública. Psicol. Cienc. prof. , 32 (2), 404-421, 2012.

SPERONI, Angela. O lugar da psicologia no hospital geral.Rev. SBPH, 9 (2), 83-97, 2006. 